\title{
Chairside Digital Workflow in Restorative Dentistry
}

\author{
Abad-Coronel Cristian* and Peña Aguilar Andrés José \\ Department of Digital Dentistry, Universidad de Cuenca, Ecuador
}

Received: 制 January 19, 2019; Published: 此 January 25, 2019

*Corresponding author: AbadCoronel Cristian, Facultad de Odontología, Campus El Paraíso, Universidad de Cuenca, Ecuador

\begin{abstract}
This is a case report of a 30-year-old male patient with diastema between his upper anterior teeth with aesthetic requirements. The case was resolved through a digital workflow with restorations designed and manufactured in the same session in which the preparations were made using a chairside system with CAD/CAM technology (Computer Aided Design / Computer Aided Manufacturing).
\end{abstract}

Keywords: Digital Workflow; Chairside CAD/CAM; Digital Dentistry

\section{Introduction}

The digital workflow in dentistry has had a rapid and effective evolution. Its application in the clinic and the laboratory improves the work of dentists, dental technicians and patient satisfaction. New technologies positively influence the diagnosis, application of new therapies, materials, and communication. Another advantage is the execution of treatments in a shorter time and with greater precision in the field of fixed prosthesis [1]. The digitalization of the workflow including scanners and printed models enables its accurate application in the clinic for linear segments [2]. Conventional techniques such as impressions by trays and impression materials have been replaced by the acquisition of the images of the preparations through the intraoral scanners.

The digital models coming from this type of impressions have a precision that allows the elaboration of ceramic crowns with the same or better results than those obtained by conventional techniques [3]. The time consumed for the preparation of the prosthesis and the comfort it entails are additional advantages for the patient when restorations are made using chairside systems that also have their limitations and indications [4]. Dental materials have evolved in conjunction with new technologies and are better adapted to the mechanical, aesthetic and functional properties of the remaining dental tissues. Ceramic, polymeric and hybrid materials can be selected according to the individual clinical needs of each patient [5]. The following is a case where digital workflow was exclusively used in a patient with minimally necessary preparations, without physical models using a chairside system, without Provisionals and with restorations of monolithic ceramic material cemented in the same clinical session.

\section{Case Report}

A 30-year-old male patient, with orthodontic treatment, in which it was planned to leave spaces between his anterosuperior teeth for restorative stage, was ready to complete the treatment (Figure 1) Once the orthodontic treatment was removed (Figure 2), a digital smile design study was carried out through photographs and videos to determine a projection of their new restorations (Figure 3). Digital waxing of the upper teeth was performed with the software (CEREC 4.5) and an STL file was obtained and exported. Model was printed using a 3D printer (Form Labs 2). A silicone matrix (ZETALabor, Zhermack) to perform the intraoral mock-up with a bisacrylic material (Protemp 4, 3M) was done to be evaluated by the clinician and the patient. Once approved, preparation guides were made using the Aesthetic Pre evaluative Technique (APT) protocol [6,7] (Figure 4).

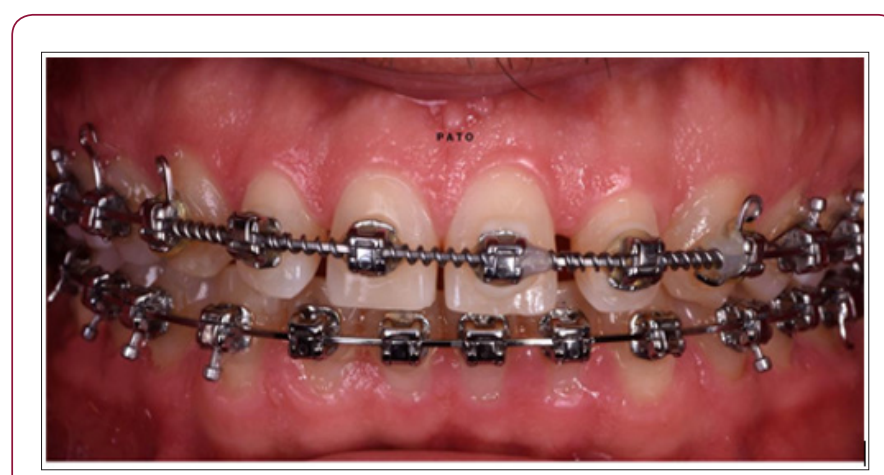

Figure 1: Orthodontic treatment. 


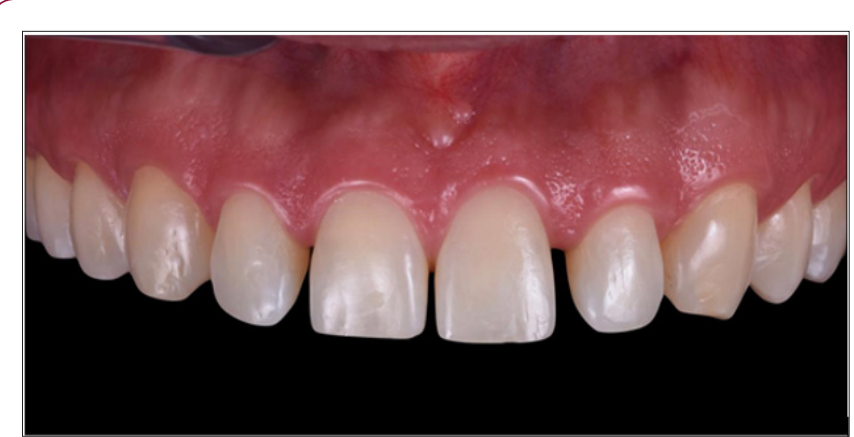

Figure 2: Upper teeth once the orthodontic treatment was finished.

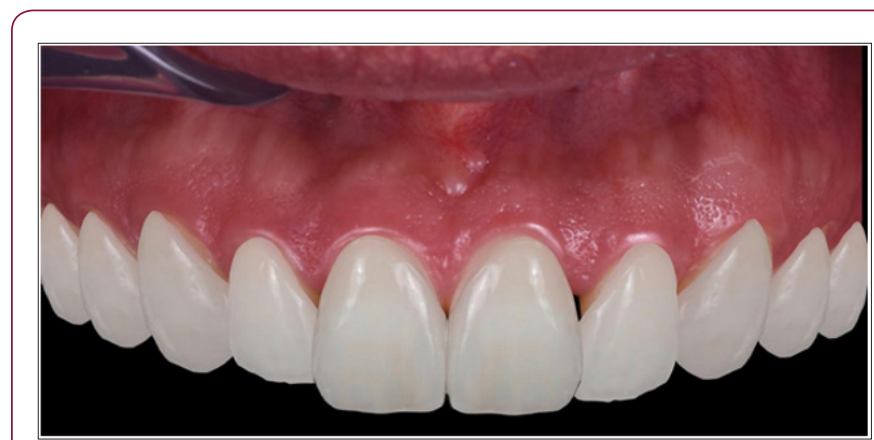

Figure 3: Digital smile design to predict shape and proportion of the new restorations.

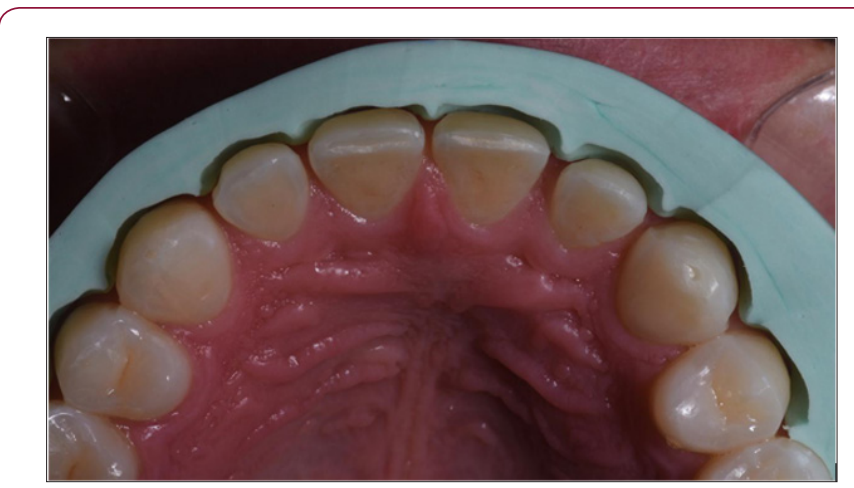

Figure 4: Minimal preparations with APT protocol.

Vertical preparations were used to avoid wearing away healthy and natural tissue, determining an insertion axis for the effect from vestibular to palatal. Separation cords (000) and (00) (Ultrapak, Ultradent) were placed (Figure 5) and digital impressions were taken using an intraoral scanner (OMNICAM, Denstply-Sirona) (Figure 6). Using the CEREC 4.5 software (Dentsply-Sirona), the restorations were designed with manual adjustments in terms of texture and anatomy using digital tools (Figure 7). Restorations were milled in feldspathic ceramic blocks through the MCXL (Dentsply-Sirona) milling machine. They finally were stain and glazed. Restorations were cemented with a light-curing resin cement (Variolink, LC, Ivoclar-Vivadent) using an absolute isolation protocol (Figure 8). Excess cement was removed and the interfaces between the dental tissue and the restorations were polished (Figure 9).

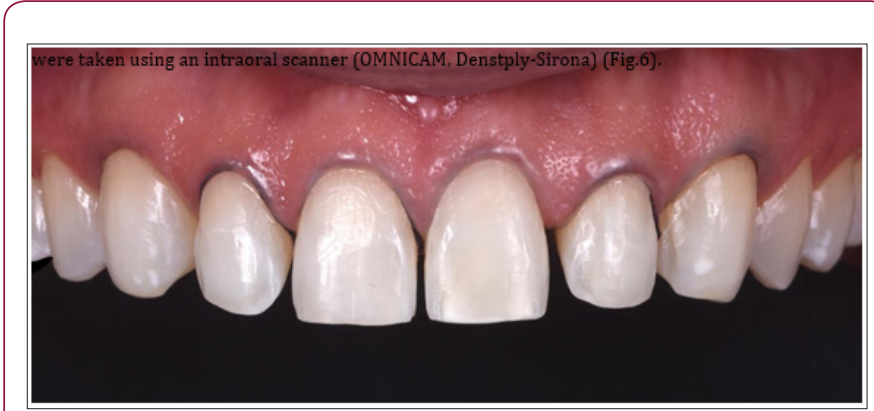

Figure 5: Vertical preparations and separation cords.

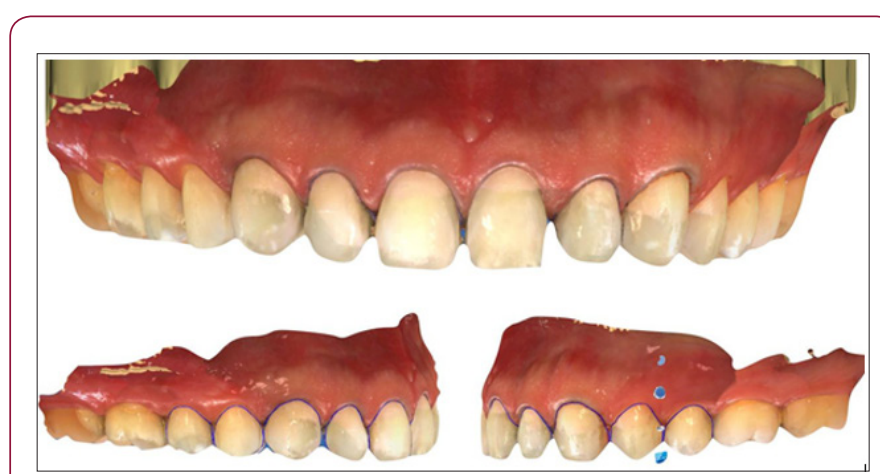

Figure 6: Digital models of the preparations.

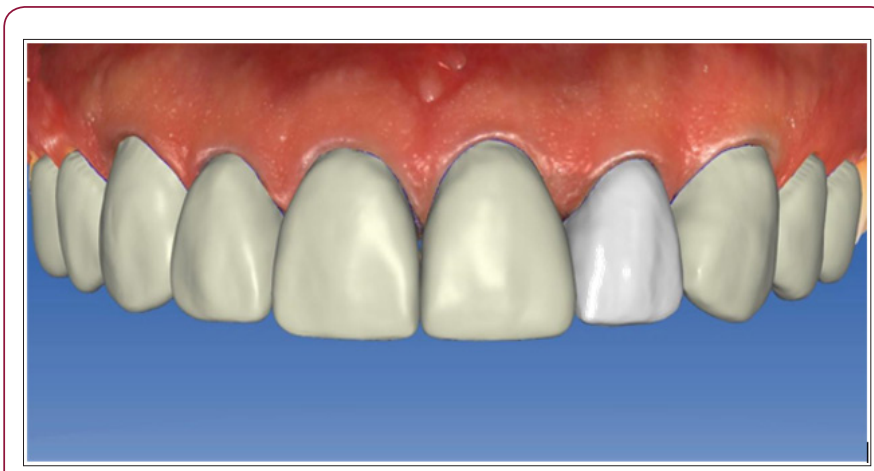

Figure 7: Computer aided design of the restorations.

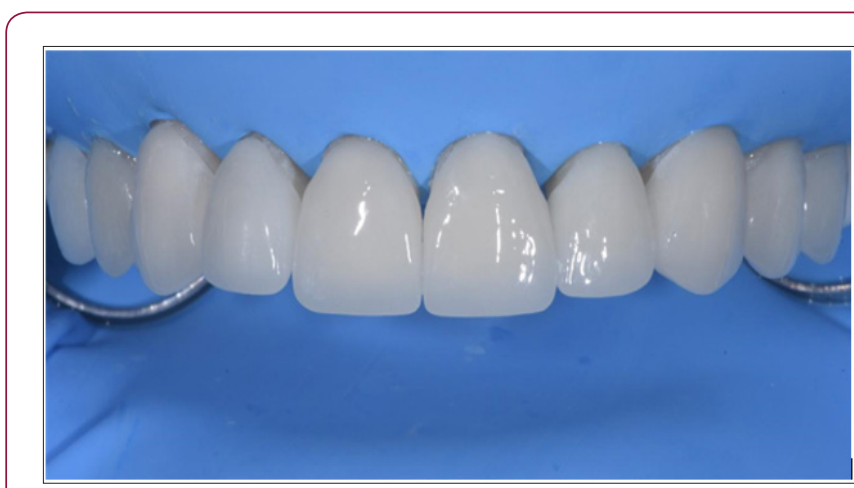

Figure 8: Adhesive Cemented Restorations with absolute isolation protocol. 


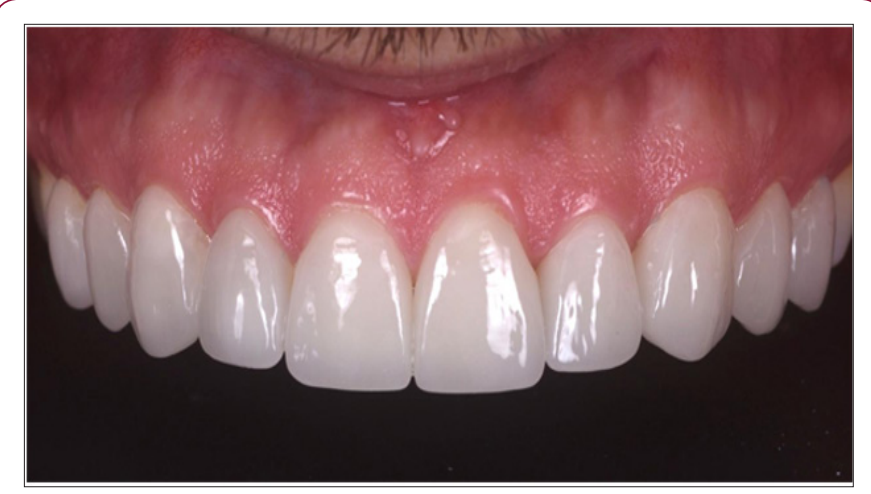

Figure 9: Restorations immediately after cementation.

\section{Discussion}

The complete digital workflow through chairside systems allows indirect restorations to be carried out in the same clinical session in which the preparations are made. This prevents temporization, inflammation of tissues, greater comfort for the patient and a rapid workflow for the dentist [8]. This in comparison with the procedures where several sessions were performed, and the laboratory work required more time between session and session [9]. The quality of the adjustment of the restorations made through CAD-CAM systems is equal to or better than the restorations performed conventionally both in the clinic [10] and in a laboratory using indirect techniques on physical models obtaining clinically acceptable results [11]. The materials used provide aesthetic properties and can be adhesively cemented improving the predictability of restorations. The design of the restorations can be replicated according to what was planned in the initial stage, so there is a greater predictability of the treatment. This procedure is limited to segments of the intraoral arch. This protocol can be applied to enough, adequate and precise preparations, as well as supra or paragingival preparations $[12,13]$. The consent and prior evaluation by the patient to perform this procedure is important, as well as the preliminary, conscious and exhaustive planning of the treatment to be performed.

\section{Conclusion}

The digital workflow applied by Chairside systems allows to make restorations with adhesively cemented materials in a predictable way and with less consumption of clinical and laboratory time, with greater comfort for the patient.

\section{References}

1. Joda T, Zarone F, Ferrari M (2017) The complete digital workflow in fixed prosthodontics: a systematic review. BMC Oral Health 17(1): 124.

2. Wesemann C, Muallah J, Mah J, Bumann A (2017) Accuracy and efficiency of full-arch digitalization and 3D printing: A comparison between desktop model scanners, an intraoral scanner, a CBCT model scan, and stereolithographic 3D printing. Quintessence Int 48(1): 41-50.

3. Berrendero S, Salido MP, Ferreiroa A, Valverde A, Pradíes G (2018) Comparative study of all-ceramic crowns obtained from conventional and digital impressions:clinical findings. Clin Oral Investig.

4. Zaruba M, Mehl A (2017) Chairside systems: a current review. Int J Comput Dent 20(2): 123-149.

5. Abad C C (2017) Dental Materials and their Innovation in Digital Dentistry. Adv Dent \& Oral Health 4(5): 555671.

6. Coachman C, Calamita MA, Sesma N (2017) Dynamic Documentation of the Smile and the 2D/3D Digital Smile Design Process. Int J Periodontics Restorative Dent 37(2): 183-193.

7. Gurel G, Morimoto S, Calamita MA, Coachman C, Sesma N (2012) Clinical performance of porcelain laminate veneers: outcomes of the aesthetic pre-evaluative temporary (APT) technique. Int J Periodontics Restorative Dent 32(6): 625-35.

8. Sannino G, Germano F, Arcuri L, Bigelli E, Arcuri C, et al. (2014) CEREC CAD/CAM Chairside System. Oral Implantol (Rome) 7(3): 57-70.

9. Sailer I, Benic GI, Fehmer V, Hämmerle CHF, Mühlemann S (2017) Randomized controlled within-subject evaluation of digital and conventional workflows for thefabrication of lithium disilicate single crowns. Part II: CAD-CAM versus conventional laboratory procedures. J Prosthet Dent 118(1): 43-48.

10. Zarauz C, Valverde A, Martinez Rus F, Hassan B, Pradies G (2016) Clinical evaluation comparing the fit of all-ceramic crowns obtained from silicone and digital intraoral impressions. Clin Oral Investig 20(4): 799806.

11. Dolev E, Bitterman Y, Meirowitz A (2019) Comparison of marginal fit between CAD-CAM and hot-press lithium disilicate crowns. J Prosthet Dent 121(1): 124-128.

12. Liebermann A, Detzer J, Stawarczyk B (2018) Impact of Recently Developed Universal Adhesives on Tensile Bond Strength to ComputerAided Design/Manufacturing Ceramics. Oper Dent.

13. Rosentritt M, Preis V, Behr M, Krifka S (2019) In-vitro performance of CAD/CAM crowns with insufficient preparation design. J Mech Behav Biomed Mater 90: 269-274.
ISSN: 2574-1241

DOI: 10.26717/BJSTR.2019.13.002431

Abad-Coronel Cristian. Biomed J Sci \& Tech Res

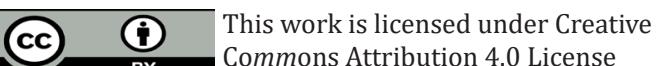

Submission Link: https://biomedres.us/submit-manuscript.php

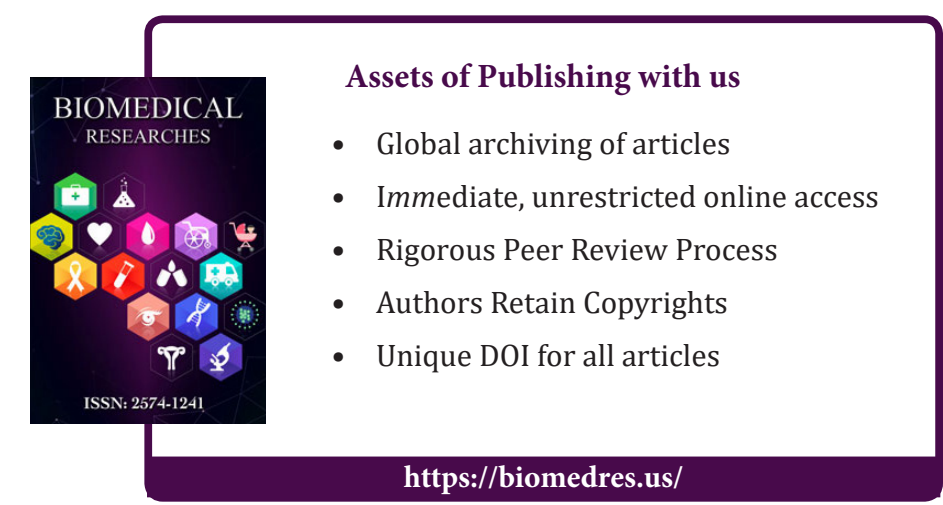

